\title{
Optogenetic tools for manipulation of cyclic nucleotides, functionally coupled to CNG-channels
}

\author{
Thilo Henss ${ }^{1}$, Jatin Nagpal ${ }^{2}$, Shiqiang $\mathrm{Gao}^{3}$, Ulrike Scheib ${ }^{4}$, Alessia Pieragnolo ${ }^{5}$, Alexander \\ Hirschhäuser ${ }^{6}$, Franziska Schneider-Warme ${ }^{7}$, Peter Hegemann ${ }^{8}$, Georg Nagel ${ }^{3}$, and \\ Alexander Gottschalk ${ }^{1}$ \\ ${ }^{1}$ Goethe-Universitat Frankfurt am Main \\ ${ }^{2}$ University College Cork \\ ${ }^{3}$ University of Würzburg \\ ${ }^{4}$ NUVISAN ICB GmbH \\ ${ }^{5}$ Università degli Studi di Padova \\ ${ }^{6}$ Philipps-Universitat Marburg \\ ${ }^{7}$ University of Freiburg \\ ${ }^{8}$ Humboldt University of Berlin
}

October 7, 2020

\begin{abstract}
Background and Purpose The cyclic nucleotides cAMP and cGMP are ubiquitous second messengers participating in the regulation of several biological processes. Interference of cNMP signalling is linked to multiple diseases and thus is an important component of pharmaceutical research. The existing optogenetic toolbox in C. elegans is restricted to soluble adenylyl cyclases, the membrane-bound Blastocladiella CyclOp and hyperpolarizing rhodopsins, yet missing are membranebound photoactivatable adenylyl cyclases and hyperpolarizers on the basis of $\mathrm{K}^{+}$-currents. Experimental Approach For the characterization of the photoactivatable nucleotidyl cyclases, we expressed the proteins alone or in combination with cyclicnucleotide gated channels in C. elegans muscle cells and cholinergic motor neurons. To investigate the extent of optogenetic cNMP production and the ability of the systems to de- or hyperpolarize the cells, we performed behavioural analyses (locomotion, muscle contraction) and measured the cNMP content in vitro. Key Results We implemented Catenaria CyclOp as a new tool for cGMP production, allowing fine-control of cGMP levels. As photoactivatable membrane-bound adenylyl cyclases, we established YFP::BeCyclOp(A-2x) and YFP::CaCyclOp (A-2x), enabling more specific optogenetic cAMP signalling compared to soluble ACs. For the hyperpolarization of excitable cells by $\mathrm{K}^{+}$-currents, we introduced the cAMP-gated $\mathrm{K}^{+}$-channel $\mathrm{SthK}$ from Spirochaeta thermophila with either bPAC or BeCyclOp(A-2x), and the Blastocladiella emersonii cGMP-gated $\mathrm{K}^{+}$channel BeCNG1 with BeCyclOp. Conclusion and Implications We established a comprehensive suite of optogenetic tools for cNMP manipulation for the nematode, which will be useful for applications in many cell types, including sensory neurons which use mainly cGMP as second messenger, and for potent hyperpolarization using $\mathrm{K}^{+}$-ions.
\end{abstract}

\section{Hosted file}

GCs_mbPACs_CNGs_elegans_Henss et al_5_10_2020 mittel.pdf available at https://authorea.com/ users/365266/articles/485439-optogenetic-tools-for-manipulation-of-cyclic-nucleotidesfunctionally-coupled-to-cng-channels 


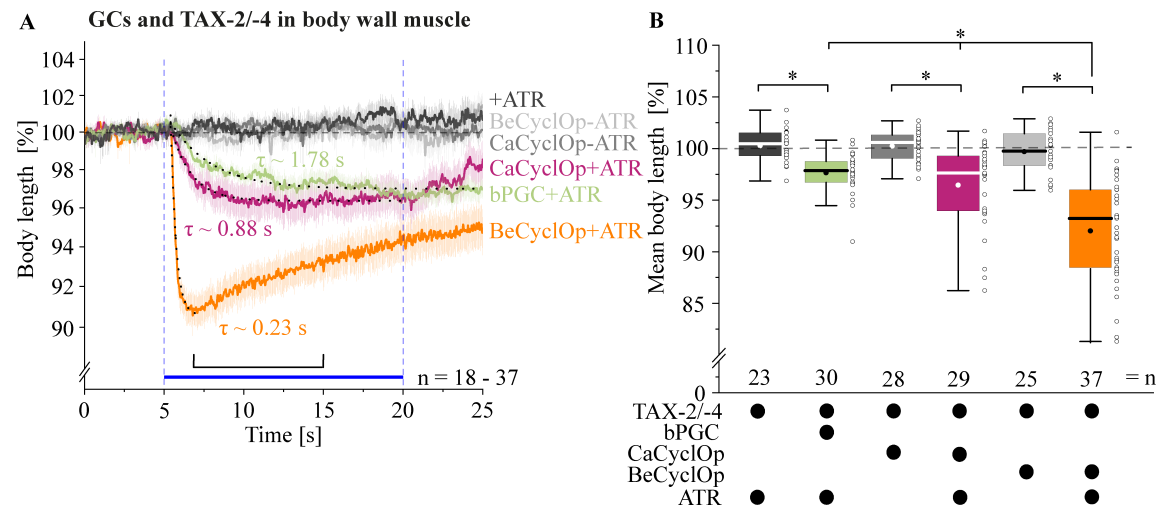

A

- lite-1(ce314)+ATR

- bPAC+ATR

- $\mathrm{CaCyclOp}(\mathrm{A}-2 \mathrm{x})+\mathrm{ATR}$
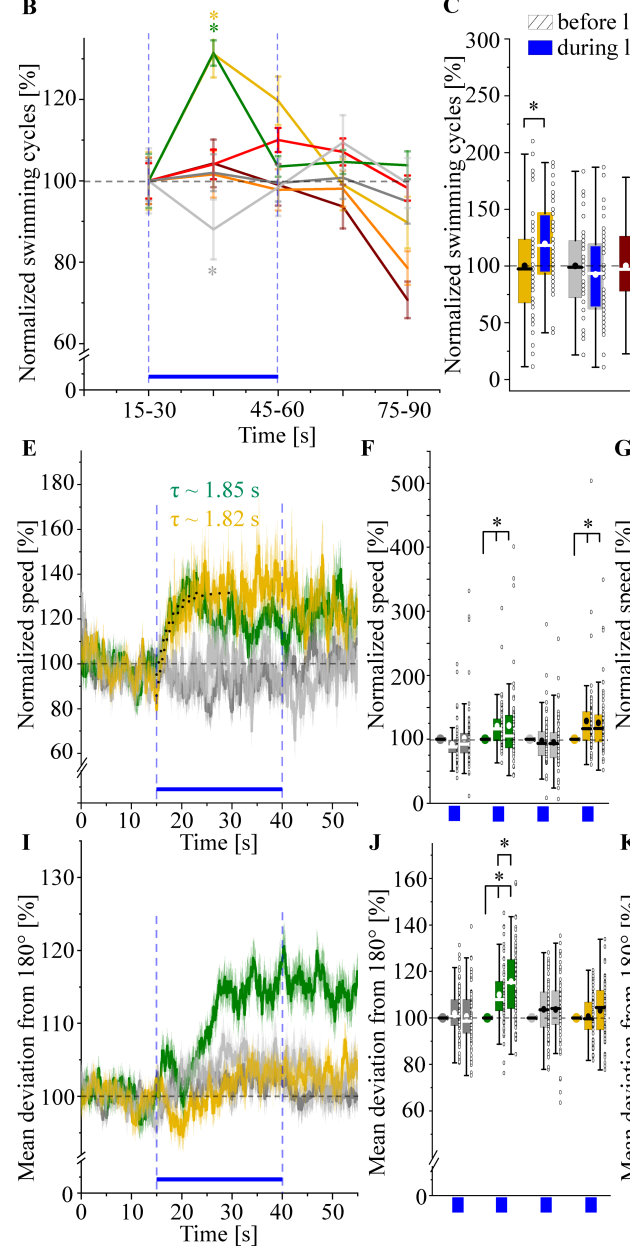

ACs in cholinergic neurons

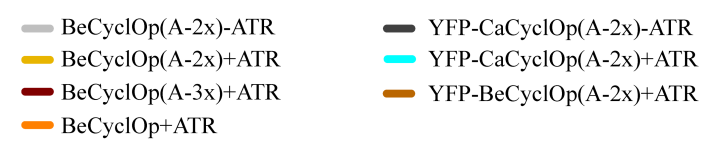

C

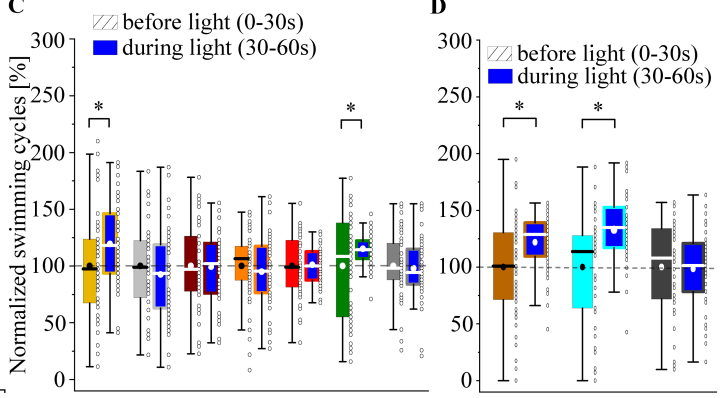

G

G $|\tau \sim 1.62 \mathrm{~s}| \quad \mathbf{H}$

H 500 -
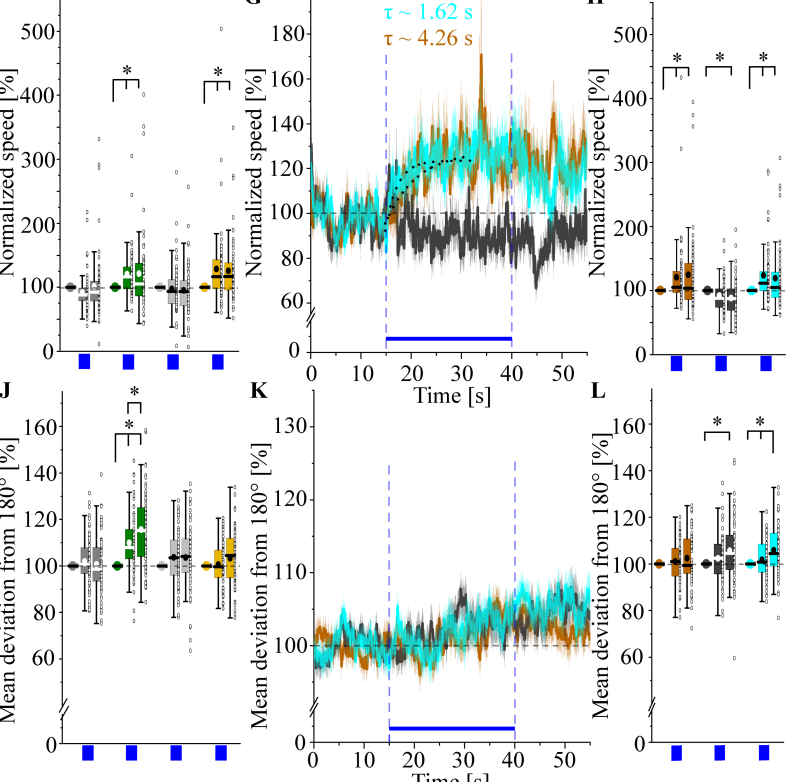


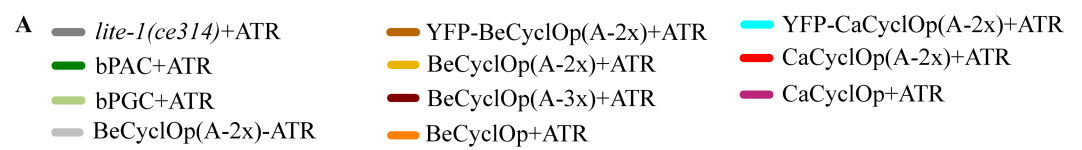

B
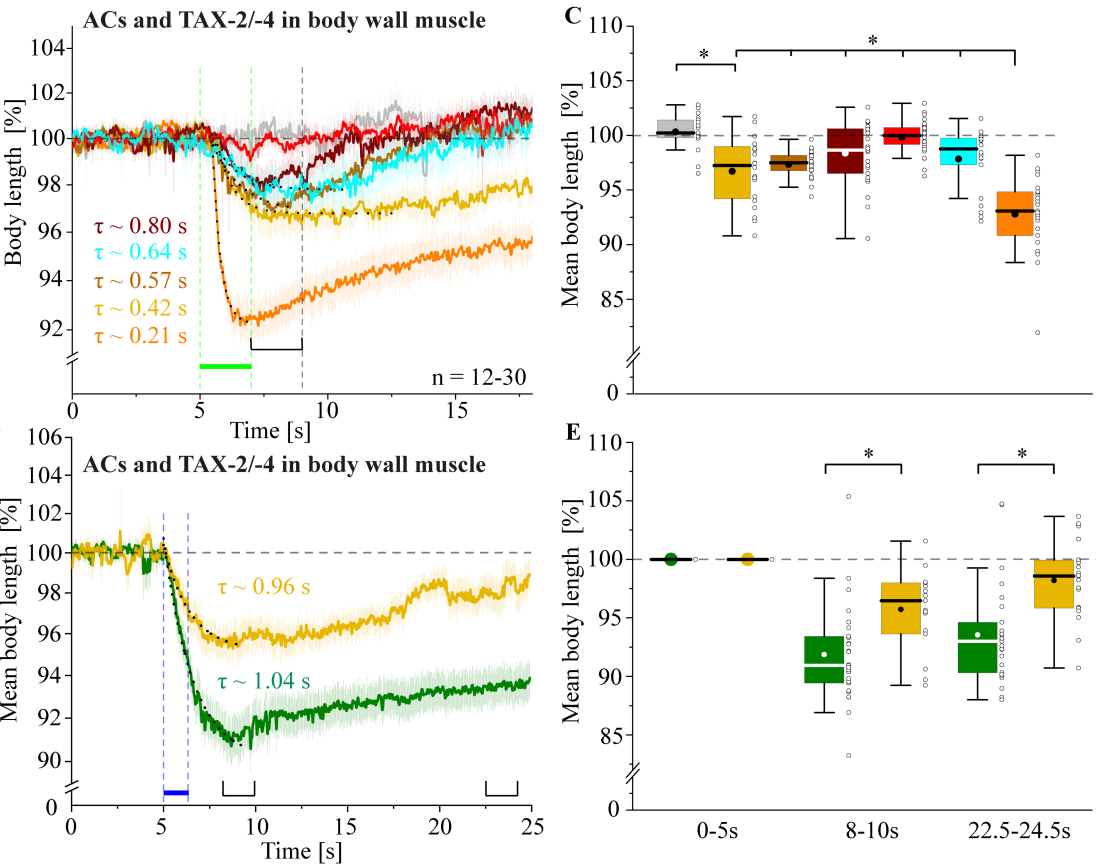

F

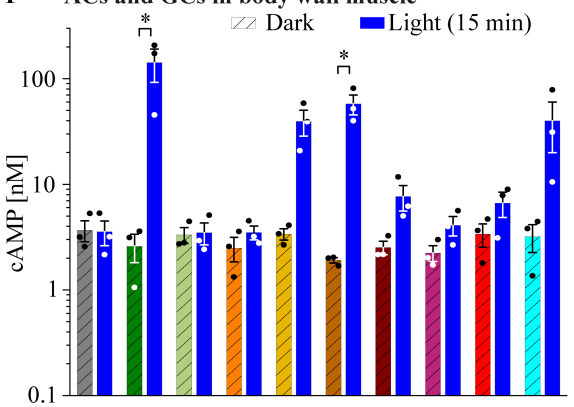

G ACs and GCs in body wall muscle

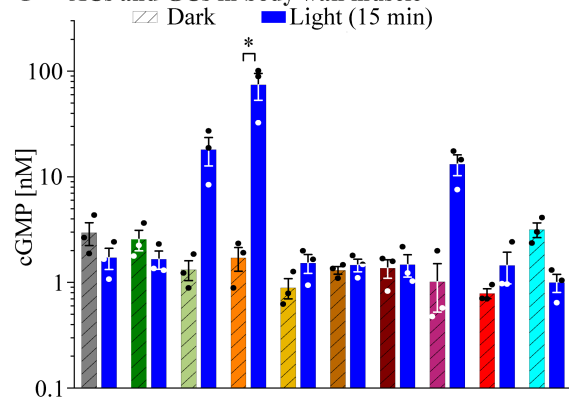



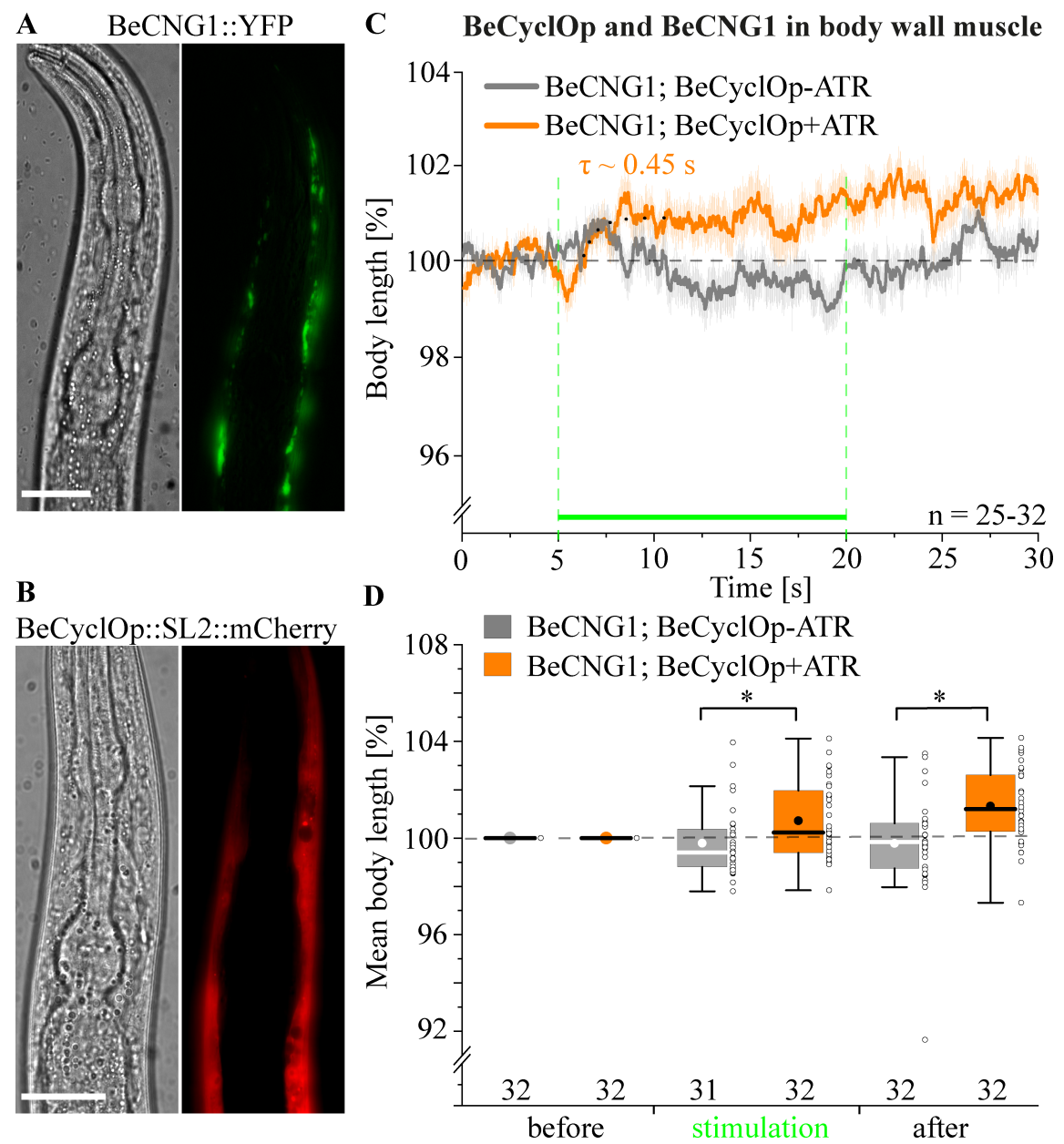


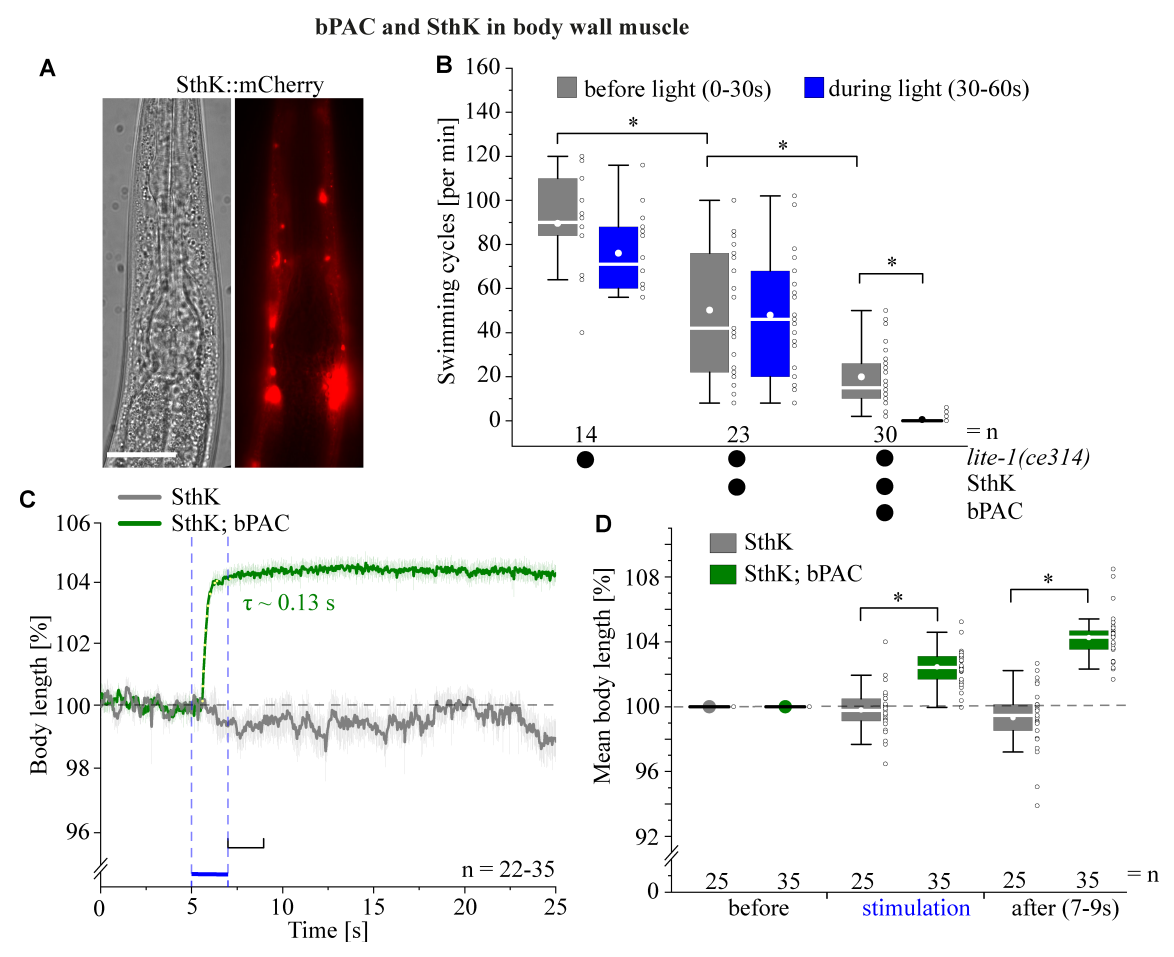


A ACs and SthK in body wall muscle
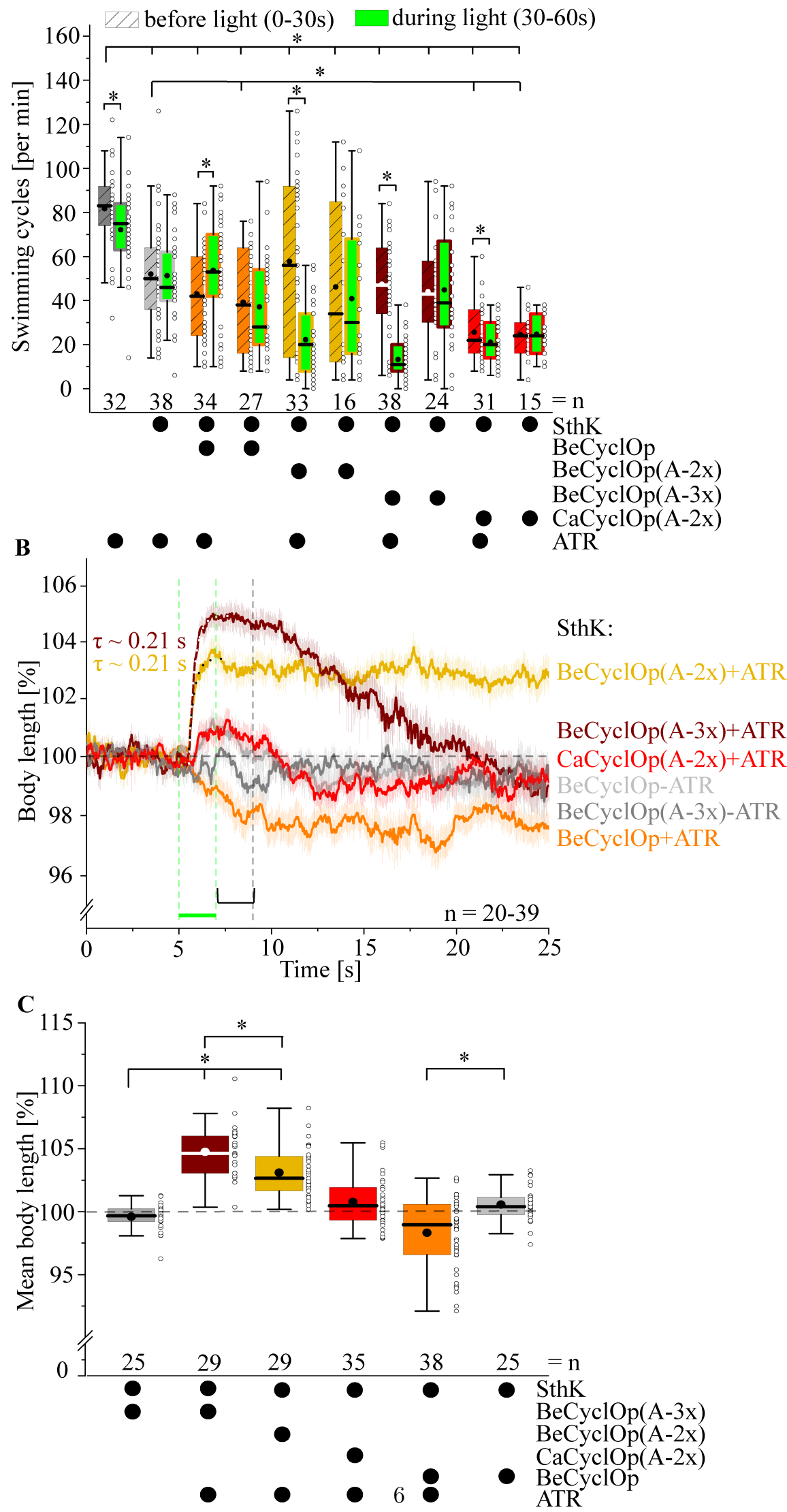


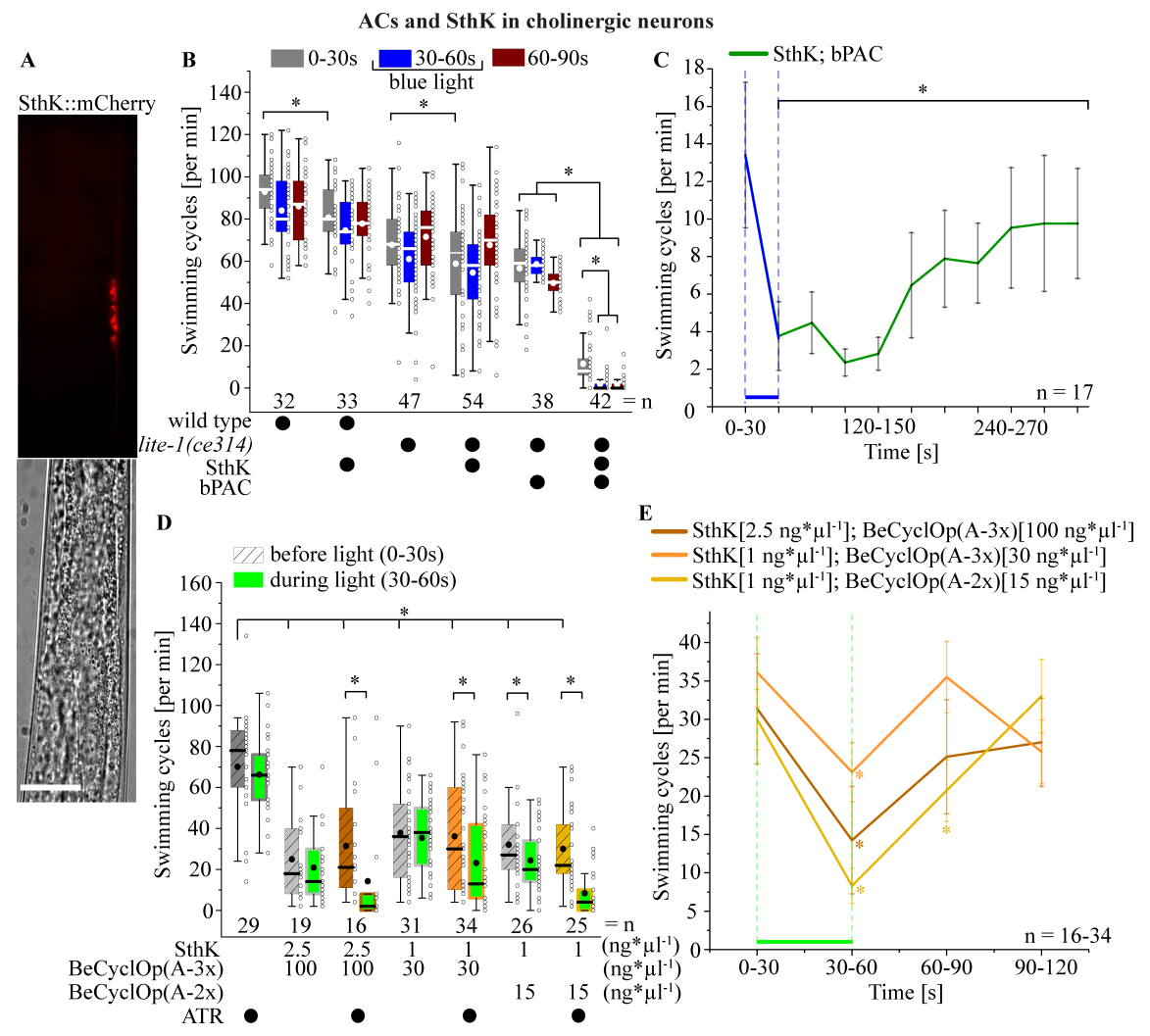




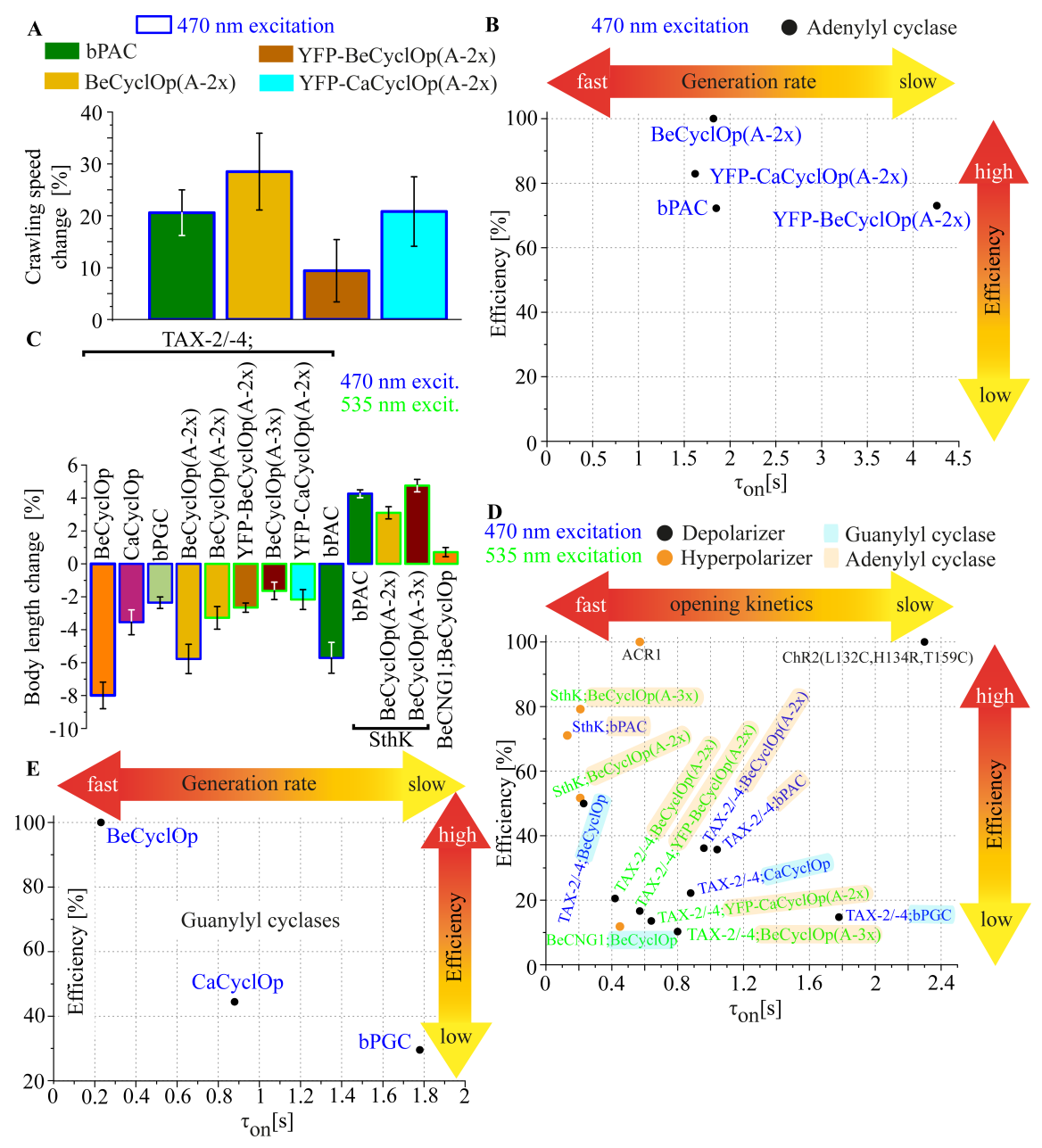

